\title{
Cultivating a global outlook and interactions in stem cell research
}

\author{
Doug Sipp ${ }^{1}$ \\ ${ }^{I}$ RIKEN Center for Developmental Biology; Kobe, Japan
}

Despite the significant commitments made to stem cell research by many national and state governments, international collaboration has been impeded by the lack of consensus on various regulatory and ethical issues, and by the inherently competitive nature of the frameworks under which such research tends to be funded. In the absence of state-level support for cross-border collaborations, organizations such as research societies and networks are developing mechanisms to promote interactions among stem cell researchers. I will give a brief overview of the current activities and plans of a number of such global and regional organizations, and suggest ways in which such groups might work in a more closely coordinated fashion in line with their shared goal of promoting the advancement of stem cell research and related fields.

Keywords: international collaboration, ISSCR, Asia-Pacific stem cell network

Cell Research (2008) 18:s179. doi: 10.1038/cr.2008.269; published online 4 August 2008

Correspondence: Doug Sipp

E-mail: sipp@cdb.riken.jp 